\title{
Private Capital Formation and Public Investment in Sudan: Testing the Substitutability and Complementarity Hypotheses in a Growth Framework
}

By

\author{
Ahmed Badawi \\ Institute for Development Policy and Management (IDPM) \\ University of Manchester
}

Comments are welcome and could be sent to:

aabab2@hotmail.com or ahmed.a.badawi@stud.man.ac.uk

\begin{abstract}
The paper attempts to address the issue of complementarity and substitutability of state capital to private sector investment activities in a neoclassical growth framework. It employs a co-integrated vector autoregressive model to account for potential endogeneity and nonstationarity problems. Results suggest that both private and public capital spending have stimulated economic growth in Sudan over the period 1970-98. The impact of private investment on real growth has been more pronounced than that of public sector investment. Public sector investment appears to have deleteriously impacted private sector physical capital expansion, implying that the impact of crowding-out categories of public sector investment has been large enough to offset any crowding-in effects. Such crowding out effect has weakened favourable positive effect that public sector's investment has exerted on growth by jeopardising private sector capital undertakings.
\end{abstract}

Keywords: cointegration, growth, investment, private, public, Sudan.

JEL Classification: C32, O11, O40, O55. 


\section{Introduction:}

The impact of government spending on private spending constitutes one of the central issues in empirical and policy debates. A widely held view envisages that the content of government's expenditure programmes and the pattern of financing these programmes have unnegligible repercussions on expenditure and saving decisions of household and corporate sectors. ${ }^{1}$ One important aspect is the impact of government capital spending and finance decisions on private sector investment. The effect of government activity on private sector activity may take two forms - direct and indirect. The direct form is where the corporate sector subsumes government saving and spending behaviour in their structural behavioural decisions on investment; the so-called ultrarationality (David and Scadding, 1974). In other words, government saving and spending variables may feature as exogenous variables in private sector utilities and expenditures functions. Under the ultrarationality hypothesis, an increase in government capital spending may crowd out private investment if the private sector views public capital investment as a substitute for private investment, and if the private sector conceives that the deficit created by public capital expenditure is taxfinanced. ${ }^{2}$ The relationship between the two types of investments is either complementary or substitutive. Such a relation, however, should be understood by distinguishing different contents of public investment.

Infrastructure investment is likely to be related in a rather different way to private capital profitability when compared to public expenditure in non-infrastructure investments. The provision of public services that reduce the cost of production of the private sector would have a positive impact on the profitability of private investment. Public investment as such is expected to be a direct complement to output produced by private sector. The displacement of private investment by public investment is likely to be large in economies where private consumption is fairly stable (so the whole crowding out falls on investment) and output is supply-constrained. In such

\footnotetext{
${ }^{1}$ See von Furstenberg and Malkiel (1977) for a thorough survey of the related literature.

2 The private sector perception of the method of deficit finance has a bearing on other sorts of crowding-out. An increase in taxation or public savings crowds out private savings (and increases private consumption) and thereby discourages investment. This sort of crowding out requires that taxes be lump sum and that the private sector perceives public savings as a substitute for private savings; for example, pension and social insurance deductions are often viewed as substitutes for private savings. For more discussion about private saving crowding-out see David and Scadding (1974).
} 
situations an ex-ante crowding out would prevail where an extra dollar of government investment would discard a dollar of private investment expenditure.

Unlike ex ante crowding out where the negative effect on private investment is due to ultrarationality, ex post or indirect crowding-out is precipitated by an increase in interest rates and cost of finance. ${ }^{1}$ Expansion in government spending exerts an upward pressure on interest rates and thereby generates a substitution of public investment for private investment. ${ }^{2}$ Assuming full employment of resources and a classical labour market, the increase in public investment and thereby rise in interest rate may displace an equal amount of private investment, causing a 100\% crowding out, irrespective of how the private sector views government actions, provided that consumption rate and demand for money are stable, and that monetary policy is unchanged. ${ }^{3}$ If resources are less than fully utilised and the economy is within its possibility frontier, expansion in public investment may partially crowd out private investment, and the magnitude of displacement of private investment depends on the responsiveness of investment and demand for money functions to interest rate changes. This partial long-run relief to private investment is due to expansion in real output following an expansionary fiscal policy.

The two types of direct and indirect (or ex ante and ex post) crowding-out described above are intimately related to demand-side impacts of government capital expansion. However, competition of public and private sectors is not only confined to the demand-side of the economy, it extends to competition over supply of resources. In an economy operating on its production possibility frontier, the involvement of the

\footnotetext{
${ }^{1}$ The terms ex ante and ex post crowding out were invoked by David and Scadding, 1974, p. 243.

${ }^{2}$ In this respect we may need to point out two things relating to increase in interest rates. First, the increase in the interest rate implies higher future obligations to the government in the form of interest payments, given that the deficit is bond-financed, and consequently generates future deficits. Second, increase in interest rate will not discourage public capital expansion for government capital expenditure is assumed exogenous, and is the cause of increase in interest rates rather than an effect of it. However, even if government decision on capital expansion is endogenously determined, interest rate would have a little effect on public investment compared to private investment. Private sector is often viewed to employ a higher rate of discount to future returns on investment than government does due to credit rationing and lack of institutional privilege.

${ }^{3}$ In fact, a rise in interest rate under ex post crowding out does not reflect a scarcity of capital resources it rather reflects scarcity of money balances due to interest-generated portfolio adjustments. Therefore if fiscal policy had been accompanied by an expansionary monetary policy, which aimed to increase money supply, private investment might have expanded or remained the same (depending on the direction of interest rate). In this respect, investment crowding-out could be thought of as a result of a restrictive monetary policy rather than a public capital expansion (Buiter, 1977, p.313).
} 
government sector in production and distribution activities may precipitate a competition with the private sector in factor markets of labour, funds, intermediate goods and so on. Crowding-out in the financial sector would be serious, given the relatively large dependence of business enterprises in developing countries on debt capital, particularly bank loans. Therefore, the private sector is prone to face stringent credit supply constraints effected by banking sector, and also exclusion from resources of non-banking financial institutions such as insurance and pension funds.

The present paper attempts to tackle the issues of complementarity and substitutability underlined above with reference to Sudan. Section two highlights some empirical evidence mainly concerned with exploring the extent and nature of the relationship between government capital spending and private investment. Section three discusses methodology employed. In section four an empirical investigation of relationship between growth and private and public investments is carried out. Section five concludes by pointing out relevant policy implications.

\section{Empirical evidence:}

In developing countries much research has been devoted to investigate the potential impact of increased public sector capital on private investment recognising the sizable state capital involvement in various economic activities. Although there has been a consensus that expansion or contraction in public investment would in principle affect private capital formation, the ultimate result of such an effect has been subject to controversy (see Binswanger, 1988; Blejer and Khan, 1984; Ermisch and Huff 1999; Galbis, 1979; Heller, 1975; Lee, 1991; Shafik, 1990; Sundararajan and Thakur, 1980). An evidence of complementarity has been found where expansion in government capital expenditure stimulates private investment by loosening supply and infrastructural constraints and thereby increasing per unit return on private investment (Aschaur, 1989; Greene and Villanueva, 1991; Wai and Wong, 1982). Government investment in infrastructure may also signify a long-term commitment of the government to its policy agenda of restructuring the economy, and thereby mollify uncertainty and incredibility, sustaining a conducive environment for private investment undertakings (Brownbridge, 1994, p.82). 
The substitutability hypothesis has not been utterly ruled out, however. von Furstenberg and Malkiel (1977) point out the theoretical possibility of a crowding-out effect, and Chhibber and van Wijnbergen (1988) provide evidence from Turkey where government investment exerts a deleterious effect on private sector investment. Government borrowing to finance budget deficits may siphon off scarce financial resources that could have been at the disposal of the private investors (the so-called financial crowding out). In the real sector of the economy, government investment spending may have a negative impact on private investment by directly competing with private investments in goods markets.

The differential impacts of government capital spending have brought about a contention that different discount rates should be used in assessing the feasibility of undertaking certain types of public investment (Ogura and Yohe, 1977). ${ }^{1}$ The relationship between private and public investments has not only been confined to issues of substitutability or complementarity or to which discount rate to be used to weigh relative importance of public spending programmes, but also extended to deal with the question that which of the private and public investments is more important to economic growth. It has been contended that the marginal productivity of private capital is greater than that of public capital and, thus, the contribution of the former to economic growth and development is larger than the latter (Beddies, 1999; Khan and Kumar, 1997; Khan, 1996; Khan and Reinhart, 1990). However, some evidence remains to point to a possibly larger contribution of public capital to economic growth (e.g. Ram, 1996).

\section{Methodology:}

Most of the empirical literature noted above attempted to analyse the relationship between private and public investments in a single structural equation framework, assuming implicitly or explicitly variables stationarity and exogeneity. The assumption of stationary variables appears to be troublesome in view of inclination of macroeconomic data to exhibit unit roots. Jones (1995) notes that aggregate

\footnotetext{
${ }^{1}$ An argument for a unique social discount rate for all projects has also been developed (Harberger, 1972; Sandmo and Dreze, 1971).
} 
investment time series, for example, tend to exhibit unit root behaviour, noting 14 nonstationery investment series out of 15 series he investigated. Endogeneity problem or simultaneity bias may also raise special concern in investment investigation, since some 'explanatory' variables may be endogenously related to investment and output. In this regard, we may exemplify by pointing out a potential endogeneity on the part of two variables commonly featured in the right-hand side of investment equations: output and public investment. While the whole of the multiplier analysis rests on defining a behavioural relationship where investment affects output or income, the reverse run of the investment-output relationship provides a battleground for the 'capital fundamentalism' controversy. In effect, the opponents of the capital fundamentalist contention suggest that causality runs from growth or output to investment (or it may be bi-directional) (see for example King and Levine, 1994; Podrecca and Carmeci, 2001; Easterly and Levine, 2001). As for public investment, most studies undertaken to look at the determinants of, or the impact of public policy on, private investment have overlooked feedback effects from other variables to public investment. While public investment exogeneity may seem empirically plausible as a characterisation of a policy variable that is wholly under government control, public investment endogeneity remains possible theoretically. Pereira (2000) argues that "the evolution of private inputs and outputs can be expected to affect the formation of public capital. Increase in private output [due to, perhaps, an increase in private investment] provides the government with a growing tax base and the potential for greater investment. Furthermore, declining private employment [due to, perhaps, a substitution effect of an increased private capital] has often led to short term policy packages that involved increased public investment [p.513]”.

Endogeneity and nonstationarity problems may be overcome by adopting a system of equations such as the vector autoregressive (VAR) system, a modelling technique introduced in the seminal work of Sim (1980). The central feature characterising the VAR technique is that it poses less restrictive structural modelling as it imposes no $a$ priori endo-exogenous division of variables; all variables entering equations system are assumed to be endogenous. Moreover, no zero restrictions are imposed on individual variables to attain identification, which is the case under simultaneous equation modelling. Also, under VAR modelling the variables' stationarity is not a prerequisite for obtaining accurate estimates and reliable hypothesis testing. Although 
VAR modelling poses the problem that it underlies no strict economic theory since all variables affect, and in turn being affected by, all variables, it can provide a sensible, economically meaningful relationships when combined with causality analysis.

When supplemented with cointegration analysis, the VAR technique allows for a rigorous modelling of the long-run relationship of non-stationary variables (Johansen, 1988; Davidson, 1998). Cointegration techniques are basically used to establish whether a long-run equilibrium or stationary relationship exists between nonstationary variables in a system of equations (or in a single equation). Such stable relationships are normally hypothesised by economic theory, which attempts to provide for logical rationale underlying the existence of an equilibrium relationship that links some variables. The concept of cointegration is in essence a statistical characterisation of a situation where the variables in the hypothesised relationship should not diverge from each other in the long run, or if they should diverge in the short run this divergence must be stochastically bounded and diminishing over time (Banerjee et al, 1993, p.136). The dependent variable in such relationships may depend not only on the level of the explanatory variables but also on the extent of deviation of the explanatory variable(s) from the equilibrium relationship with the dependent variable. This sort of behaviour is usually captured by the error correction models (ECMs) which describe the interaction between short-term and long-term impacts in a given relationship (e.g. Hendry and Anderson, 1977; Davidson et al, 1978). In other words, long-run features of endogenous variables are preserved to act as a feedback mechanism in short-term dynamics.

The methodology employed in this study blends different, yet related concepts, underlined above. Cointegration analysis is combined with the VAR technique (the so-called 'cointegrated VAR') to account for problems of nonstationarity and endogeneity in order to estimate relevant coefficients and parameters that describe short and long run interactions of growth, private investment, and public sector investment. ${ }^{1}$

\footnotetext{
${ }^{1}$ Similar applications to cointegrated VAR technique though scant are found in Ghali (1998), Naqvi (2002) and Pereira (2001).
} 


\section{Empiricism:}

\section{Unit root tests and cointegrated VAR model:}

Testing for unit roots in data conventionally precedes cointegration analysis. Augmented Dicky-Fuller (ADF) test is often employed to determine degree of integration of variables; how many times should a variable be differenced to attain stationarity (Dicky and Fuller, 1979, 1981). We run ADF test equation

$$
\Delta y_{t}=\mu+\gamma T+\beta y_{t-1}+\sum_{i=1}^{k} \lambda_{i} \Delta y_{t-i}+u_{t}
$$

where $y_{t}$ is the variable in question, $T$ is a time trend, $k$ is lag length, and $u_{t}$ is a random variable assumed to be 'white noise'. Equation (1) is applied to variables $Y, I$, $P S I, C R$, and $R$ defined as

$$
\begin{aligned}
& Y \equiv \log \text { of real output, } \\
& I \equiv \log \text { of real private investment, } \\
& P S I \equiv \log \text { of real public sector (government and public enterprises) investment, } \\
& C R \equiv \log \text { of real banking sector's credit to the private sector, } \\
& \text { and } \\
& R \equiv \text { real lending rate on banking sector's advances to the private sector. }
\end{aligned}
$$

Variables $C R$ and $R$ are included in the model because they appear too often in private investment equations in developing countries. ${ }^{1}$ Unit roots test results are reported in table (1) where ADF $t$-statistic $(\hat{\beta} / s . e(\widehat{\beta}))$, lag length $k$, $t$-statistic for trend variable are reported. ${ }^{2}$ The results indicate that all variables are nonstationary with a significant trend at $10 \%$ and less level of significance. Running $A D F$ tests for change in variables indicates that all variables are integrated of order one $(I(1))$, i.e. they need to be differenced once to attain stationarity (see table (1)).

\footnotetext{
${ }^{1}$ For thorough discussion about empirical investment equations in developing countries see Rama (1990).

${ }^{2}$ Determination of the lag length $k$ is based on Akaike Information and Schwarz Bayesian Criteria.

The two criteria produce the same lag length for all variables.
} 
Table (1): Unit Root Test Using ADF Procedure

\begin{tabular}{clcc}
\hline & $k$ & ADF & $t$ trend: $\hat{\gamma} /$ s.e $(\hat{\gamma})$ \\
\hline$Y$ & 0 & -1.33 & $1.68(0.10)$ \\
$\Delta Y$ & 0 & -6.1 & $2.17(0.04)$ \\
$I$ & 0 & -1.95 & $2.1(0.05)$ \\
$\Delta I$ & 0 & -5.34 & $1.65(.10)$ \\
$P S I$ & 2 & -2.4 & $-3.4(0.00)$ \\
$\Delta P S I$ & 0 & -4.8 & $-0.96(0.35)$ \\
$C R$ & 1 & -1.19 & $-2.6(0.02)$ \\
$\Delta C R$ & 0 & -4.4 & $-1.18(0.25)$ \\
$R$ & 0 & -1.61 & $-2.3(0.03)$ \\
$\Delta R$ & 0 & -4.4 & $-1.32(0.2)$ \\
\hline
\end{tabular}

\# Critical values for ADF-statistics are 5\%=-3.61 and 1\%=-4.39 (values are produced by PcGive and found in Dickey and Fuller (1979)). Critical values for $t$ statistics are conventional values. $p$ values in parentheses are conventional $p$ probabilities for $t$ statistics.

Nonstationarity of variables noted above clearly justifies adopting VAR system of equations. Technically, endogenous variable under VAR system is explained by the lagged values of the variable and lagged values of all other variables in the system. Consider the unrestricted VAR model

$$
Z_{t}=A_{0} D_{t}+A_{1} Z_{t-1}+A_{2} Z_{t-2}+\cdots+A_{k} Z_{t-k}+\epsilon_{t}
$$

where $Z$ is an $n .1$ vector containing all $n$ variables in the system, $D$ is a vector holding deterministic terms (intercept, trend, dummies, etc..), and $\in$ is an $n$ dimensional vector of multivariate random errors with mean zero and covariance matrix $\sum$. The VAR system in equation (2) can also be represented in the form

$$
\Delta Z_{t}=A_{0} D_{t}+\prod Z_{t-1}+\Gamma_{1} \Delta Z_{t-1}+\Gamma_{2} Z_{t-2}+\cdots+\Gamma_{k-1} \Delta Z_{t-k+1}+V_{t} .
$$

Equation (3) is simply an error correction representation of the VAR system embodied in equation (2), and shows how level of the endogenous variables in $Z$ enter short-term dynamics. The main concern of cointegration is to determine the rank of the long-run matrix $\Pi$; the determination of maximum number of linearly independent columns in matrix $\Pi$. Since matrix $\prod$ is of order $n \times n$, the maximum possible rank is $n$ and the minimum rank is zero. When the rank of $\prod$ is zero, matrix П only contains zero elements, and the short-term dynamics do not depend on the levels of any of the variables in vector $Z$. Growth of variables in $Z$ solely depends on 
lagged changes in all variables. On the other extreme, an $n$ rank implies all endogenous variables in $Z$ are $I(0)$. The statistical hypothesis under cointegration is $\mathrm{H}(p)$ : $\operatorname{rank}(\Pi) \leq \mathrm{r}$, where $\mathrm{r}$ is the rank of the long-run matrix. Under the null hypothesis, matrix $\prod$ can be decomposed into a product of two non-null matrices such that $\Pi=\alpha \beta^{\prime}$. Matrices $\alpha$ and $\beta$ hold adjustment coefficients and long-run parameters respectively, and both matrices are of $n \times r$ dimension. Although the rank determination of the long-run matrix $\prod$ provides an answer as to how many linear combinations of variables in the system are $I(0)$, it requires to be supplemented by exogeneity and causality analysis to provide an economically interpretable linear relations.

\section{Co-integrated finite vector autoregressive system and stationary long-run relationships:}

The matrix $Z$ comprises of five variables: $Y, I, P S I, C R$, and $R$, spanning annual data over the period 1970-98. Hence the system composes of five estimable equations whose variables are $I(1)$. The matrix $D$ (the deterministic matrix) holds an unrestricted constant; the constant does not enter the cointegrating space of long-run relations. ${ }^{1}$ The order of the VAR or the lag length is set to two, hence $\operatorname{VAR}(2){ }^{2} \mathrm{We}$ employ PcGive, which is based on Johansen (1988), to determine cointegration rank $r$ and estimate adjustment coefficients $\alpha s$ and cointegrating vector(s) $\beta$. Results are reported in table (2). Cointegration test statistics for the five-variables, second-order VAR of $Y, I, P S I, C R$, and $R$ indicate that one cointegrating vector exits. The null hypothesis that there is no cointegrating vector in the system $(r \leq 0)$ is rejected, but the null that there exists at most one cointegrating vector $(r \leq 1)$ is not. This is indicated by that for $H_{0}: \mathrm{r} \leq 0$ the trace statistic reports a magnitude of 75.48 which is insignificant (greater than the critical value 71.68) at 5\%, while for $H_{0}: r \leq 1$ the trace statistic reports a significant magnitude of 40.16 which is less than the critical value 47.94 (panel (a) in table (2)). Variables in the system move together towards a

\footnotetext{
${ }^{1}$ We comply with a suggestion by Doornik and Hendry (2001), p.40, to un-restrict constant when data exhibit a nonstationary behaviour, allowing for a non-zero drift in any unit-root process.

${ }^{2}$ Determination of the lag length in the VAR system is a crucial issue, since the cointegration rank and resulting output are sensitive to dynamic structure of the system. To set the lag length we followed a rather ad hoc yet statistically appropriate procedure. We ran a VAR system with a reasonably high lag length of four and then adopted a general-to-specific procedure to reach to a suitable lag length of two.
} 
stationary, long-run equilibrium state defined by the cointegrating vector. The unrestricted standardised estimates for the cointegrating vector $\beta$ and its respective feedback adjustment coefficients $\alpha$ s are reported in panels (b) and (c) in table (2) alongside respective $t$ ratios. The cointegrated long-run relationship with adjustment coefficients or loading parameters corresponds to the term $\left(\prod Z_{t-1}\right)$ or $\left(\alpha \beta^{\prime} Z t-1\right)$ in equation (3). This term embodies the error correction term $\left(\beta^{\prime} Z t-1\right)$ that to enter short-term vector error correction model (VECM).

Table (2): Cointegration rank, Unrestricted Cointegrated Vector and Adjustment Coefficients

(a) I(1) Cointegration analysis and testing for cointegration rank $r$ :

\begin{tabular}{cccc}
\hline$H_{0}: r \leq$ & Trace statistics & Eigenvalues & $p$-value \\
\hline 0 & 75.48 & 71.68 & 0.02 \\
1 & 40.16 & 47.94 & 0.22 \\
2 & 21.88 & 34.72 & 0.32 \\
3 & 9.94 & 21.49 & 0.29 \\
4 & 3.17 & 10.69 & 0.10 \\
\hline
\end{tabular}

(b) Unrestricted standardised eigenvector $\beta^{\prime}$ :

\begin{tabular}{cccccc}
\hline & $Y$ & $I$ & $P S I$ & $C R$ & $R$ \\
\hline \multirow{2}{*}{$\beta^{\prime}$} & 1.0 & -0.89749 & -0.19906 & 1.1130 & -5.6792 \\
& (rest.) & $(-7.648)$ & $(-3.14)$ & $(5.988)$ & $(-17.748)$ \\
\hline
\end{tabular}

(c) Unrestricted standardised adjustment coefficients $\alpha$ :

\begin{tabular}{cc}
\hline & $\alpha$ \\
\hline$Y$ & $-0.39713(-1.986)$ \\
$I$ & $0.85780(2.187)$ \\
$P S I$ & $-0.20537(-0.423)$ \\
$C R$ & $-0.021988(-0.099)$ \\
$R$ & $0.078905(2.454)$ \\
\hline
\end{tabular}

As shown in table (2) above both private and public sector investments have a positive significant long-run impact on real output. Since coefficients on $I$ and PSI could be interpreted as long-run elasticities of real output with respect to both types of investment, private investment reports a larger elasticity of nearly 0.9 compared to that reported for public sector investment (0.20). Further, private investment seems to adjust to long-run equilibrium path much quicker than public sector investment. This 
is indicated by the larger magnitude of the loading parameter $\alpha$ reported for private investment (see panel (c) in table (2)).

\section{Long-run weak exogeneity and Granger causality:}

Adjustment or loading coefficients $\alpha$ s may also infer some information about variables long-run weak exogeneity with respect to cointegrating vector. It can be seen from table (2) that $\alpha$ s on PSI and $C R$ appear to be insignificant, indicating a long-run weak exogeneity with respect to the cointegrating vector; both variables are cointegrated with trend movements in other variables in the system, while in the short-term they respond only to changes in other variable. On contrast, $Y, I$, and $R$ appear with significant loading coefficients. This rudimentary inference is supplemented by formal tests for long-run weak exogeneity, and results are reported in table (3) below. Respective $\alpha$ coefficients on variables are linearly restricted to equal zero, preserving the cointegration rank of one. The restricted coefficients are then tested (separately) for weak exogeneity. The linear hypotheses of zero alphas on $P S I$ and $C R$ are accepted since associated likelihood ratios $C h \hat{i}^{2}$ report respective values of 0.21 and 0.01 , which are highly insignificant ( $p$-probability in parentheses). Long-run weak exogeneity does not however characterise $I$ and $R$ as the long run equilibrium relationship tends to have a significant feedback effects on real private investment and real interest rate. Similar $C h \hat{i}^{2}$ tests for weak exogeneity of $I$ and $R$ report magnitudes of 4.08 and 6.15 which are highly significant, enabling us to easily reject the null of weak exogeneity.

Table (3): Tests for Long-Run Weak Exogeneity

( $H_{0}$ : Variable is weakly exogenous to cointegrating vector)

\begin{tabular}{cccc}
\hline & $C h \hat{i}^{2}($ prob. $)$ & Decision over $H_{0}$ & Inference \\
\hline$Y$ & $3.55(0.06)$ & Rejection & Not exogenous \\
$I$ & $4.08(0.04)$ & Rejection & Not exogenous \\
$P S I$ & $0.21(0.65)$ & Acceptance & Exogenous \\
$C R$ & $0.01(0.92)$ & Acceptance & Exogenous \\
$R$ & $6.15(0.01)$ & Rejection & Not exogenous \\
\hline
\end{tabular}


In addition to testing for exogeneity of $P S I, C R$, and $R$, we run similar test for weak exogeneity of $Y$. The latter sort of exogeneity tends to have important implications for investment equation. In investment analysis based on a single equation framework, the feedback impact from investment to income, the so-called simultaneity problem, is usually neglected by assuming a priori that income is weakly exogenous to investment. The null hypothesis that real output is weakly exogenous is rejected at $10 \%$ level of significance with $C h \hat{i}^{2}=3.55$, indicating that a significant long-run stationary feedback to $Y$ exists. This result seems in contrast to those found by Ghali (1998) and Nagvi (2002) for the cases of Tunisia and Pakistan respectively. They report a weakly exogenous real output. When such a significant feedback effect on output exists, a single investment equation that disregards it by assuming a priori weak exogeneity of real output or income, would likely to result in inefficient and inconsistent estimates.

Considering inferences in table (3), the long-run exogeneity of $P S I$ and $C R$ are utilised to re-estimate the system, preserving the cointegration rank of one and imposing two long-run zero restrictions on respective adjustment coefficients on PSI and $C R$ (no restrictions are imposed on $\beta s$ apart from identification restrictions). Resultant restricted standardised $\alpha$ s and $\beta$ s are reported in table (4). Results for restricted $\beta$ s and $\alpha$ s do not seem to have changed significantly from those reported in table (2). Both private and public investments remain to have significantly positive impacts on real output with private investment reporting larger elasticity. These results tend to be qualitatively and quantitatively different from those reported in Ghali (1998) for the case of Tunisia. Ghali reports larger magnitudes for output elasticities with respect to private and public investments of around 1.7 and 2.0 respectively. While private investment appears to have affected real output positively in Tunisia, public sector investment reports a negative elasticity.

Table (4): Restricted Cointegrated Vector and Adjustment Coefficients

$$
\left(\alpha_{2}=\alpha_{3}=0\right)
$$

(a) Restricted standardised eigenvectors $\beta^{\prime}$ :

\begin{tabular}{cccccc}
\hline & $Y$ & $I$ & $P S I$ & $C R$ & $R$ \\
\hline \multirow{2}{*}{$\beta^{\prime}$} & 1.00 & -0.90744 & -0.20834 & 1.1314 & -5.7359 \\
& (rest.) & $(-7.603)$ & $(-3.232)$ & $(5.985)$ & $(-3.616)$ \\
\hline
\end{tabular}


(b) Restricted standardised adjustment coefficients $\alpha$ :

\begin{tabular}{cc}
\hline & $\alpha$ \\
\hline$Y$ & $-0.35868(-2.318)$ \\
$I$ & $0.88523(2.437)$ \\
$P S I$ & 0.00 (rest.) \\
$C R$ & 0.00 (rest.) \\
$R$ & $0.080789(2.299)$ \\
\hline$\# t$ statistics in parentheses &
\end{tabular}

\# $t$ statistics in parentheses

In addition to long-run weak exogeneity, we test for causality using Granger tests which are widely used for their operationality. These tests were invoked in Granger (1969), developed in Sargent (1976), and discussed in, among others, Charemza and Deadman (1997). A variable $x$ is a Granger cause of $y$, denoted $x \rightarrow y$, if present values of $y$ can be predicted more accurately, citrus paribus, by using past values of $x$ rather than by not doing so. Formally, it is possible to test for non-causality from $x$ to $y$ by testing for the hypothesis that all parameters on lagged values of $x$ in an autoregressive equation of $y$ are equal to zero. Such a restriction could be tested for straightforwardly by using F-test or the Lagrange Multiplier (LM) test. ${ }^{1}$ Acceptance of the joint hypothesis that all parameters on lagged values of $y$ are not different from zero would imply that $y$ does not Granger-cause $x$.

We use VAR representation in difference of variables with only intercept in deterministic part to test for Granger causality. ${ }^{2}$ Granger test results based on the stationary VAR model are reported in table (5). Results indicate that $I, P S I$, and $R$ do Granger-cause $Y$, while $Y$ does granger cause $I$ and $R$ but not $P S I$ and $C R$. A bidirectional causality seems to exist between $Y$ and $I$, and $Y$ and $R$. Both $I$ and $R$ are Granger-caused by $Y$ and hence can be predicted better by using information on past values of $Y\left(Y_{t-1}, Y_{t-2}, \ldots\right)$ rather than by not doing so. Testing for 'collective' causality running from other variables to $Y$ and vice versa indicates a bi-directional causality between real output and explanatory variables. It is apparent from the above discussion about weak exogeneity and Granger causality that PSI and CR are the only variables in the system that are super or strongly exogenous with respect to the

\footnotetext{
${ }^{1}$ See Charemza and Deadman (1997), pp.166-67, for a detailed and expository description of the computation of LM statistics in the context of Granger causality.

${ }^{2}$ Employing the VAR representation in levels may raise some doubts about its results since it contains nonstationary or $I(1)$ variables, though sufficient parameterisation of the autoregressive process and introduction of trend to deterministic component may mitigate nonstationarity problem.
} 
cointegrating vector, since both variables are weakly exogenous as well as Grangercausing $\mathrm{Y}$ but not Granger caused by $\mathrm{Y}$. In this sense they meet the strong exogeneity definition provided in Engle et al $(1983,1994){ }^{1}$

Table (5): Granger Tests for Causality

\begin{tabular}{ccc}
\hline & $C h \hat{i}^{2}($ prob. $)$ & Inference \\
\hline$I \rightarrow Y$ & $7.869(0.09)$ & Causality \\
$Y \rightarrow I$ & $7.64(0.09)$ & Causality \\
$P S I \rightarrow Y$ & $9.645(0.008)$ & Causality \\
$Y \rightarrow P S I$ & $0.324(0.85)$ & No causality \\
$C R \rightarrow Y$ & $0.782(0.677)$ & No causality \\
$Y \rightarrow C R$ & $1.98(0.372)$ & No causality \\
$R \rightarrow Y$ & $6.803(0.033)$ & Causality \\
$Y \rightarrow R$ & $7.22(0.027)$ & Causality \\
Other variables $\rightarrow Y$ & $18.371(0.019)$ & Causality \\
$Y \rightarrow$ other variables & $16.864(0.036)$ & Causality \\
\hline
\end{tabular}

\section{Short-term dynamics and the I(0) system:}

The cointegrating vector $\beta^{\prime}$ in table (4) constitutes a restricted long-run stationary relationship, and describes the error correction term

$$
E C T=Y-0.907 * I-0.208 * P S I+1.131 * C R-5.74 * R .
$$

Short-term dynamics or the $I(0) \operatorname{VAR}(1)$ system comprises of five equations of changes in $\mathrm{Y}, I, P S I, C R$, and $R$. The system is estimated by unrestricted ordinary least squares and results obtained are reported in table (6). ${ }^{2}$ Private investment reports a significantly positive short-term impact on growth, while public sector investment appears with a significantly negative effect on it. Further, public sector investment

\footnotetext{
${ }^{1}$ Strong exogeneity is essential for models formulated basically for forecasting (Engle et al, 1983). Any forecast based on parameters obtained from a single structural equation incorporating variables that are not strongly exogenous would indeed be doubtful. In this context, incorporating non-strongly exogenous variables (such as $I$ and $R$ ) in a single growth equation without accounting for feedbacks from output may vitiate any prediction about future growth. However results of such equation are still valid for purposes of statistical inferences (estimation and hypothesis testing) as long as explanatory variables demonstrate weak exogeneity to output (Ericsson et al, 1998, p.370).

${ }^{2}$ Since all variables in the short-term system are $I(0)$, conventional test statistics such as $t, c h i^{2}$, and $\mathrm{F}$ statistics are valid and can be used for inferences about coefficients' significance.
} 
appears to have a significantly negative effect on private investment. Since public sector investment is an amalgam of different categories of government (and its enterprises) capital expenditure in fixed assets, the negative crowding out impact that public sector investment has on private investment implies that the crowding out effect induced by substitutive government investments has been larger than crowding in effect (if there has been any) caused by complementary government investments.

Table (6): Short-Term Vector Error Correction Model

\begin{tabular}{|c|c|c|c|c|c|}
\hline & $\Delta Y$ & $\Delta I$ & $\triangle P S I$ & $\triangle C R$ & $\Delta R$ \\
\hline \multirow[t]{2}{*}{ Const. } & 2.591 & -5.369 & 1.138 & 0.102 & -0.524 \\
\hline & $(2.01)$ & $(-2.13)$ & $(0.365)$ & $(0.072)$ & $(-2.54)$ \\
\hline \multirow{2}{*}{$\Delta Y_{-1}$} & -0.104 & -0.509 & -0.295 & 0.311 & 0.067 \\
\hline & $(-0.438)$ & $(-1.10)$ & $(-0.515)$ & (1.19) & (1.77) \\
\hline \multirow{2}{*}{$\Delta I_{-1}$} & 0.162 & 0.039 & -0.172 & -0.174 & 0.044 \\
\hline & (2.06) & $(0.144)$ & $(-0.513)$ & $(-1.13)$ & (1.99) \\
\hline \multirow{2}{*}{$\Delta P S I_{-1}$} & -0.36 & -0.284 & 0.088 & 0.109 & -0.008 \\
\hline & $(-1.99)$ & (1.97) & $(0.344)$ & $(0.931)$ & $(-0.481)$ \\
\hline \multirow{2}{*}{$\Delta C R_{-1}$} & 0.482 & 0.57 & 0.256 & 0.394 & 0.015 \\
\hline & (1.55) & (1.96) & $(0.405)$ & (1.36) & (0.357) \\
\hline \multirow{2}{*}{$\Delta R_{-1}$} & -2.218 & -6.049 & -0.552 & -1.735 & 0.177 \\
\hline & $(-1.58)$ & $(-2.20)$ & $(-0.162)$ & $(-1.12)$ & $(0.786)$ \\
\hline \multirow{2}{*}{$E C T_{-1}$} & -0.390 & 0.839 & -0.179 & -0.022 & 0.079 \\
\hline & $(-1.98)$ & (2.17) & $(-0.373)$ & $(-0.099)$ & $(2.49)$ \\
\hline \multirow{2}{*}{$\begin{array}{c}\text { Serial correlation AR } 1-2 \\
\text { test: } F(4,17)\end{array}$} & 1.895 & 1.958 & 1.223 & 1.764 & 0.637 \\
\hline & $(0.158)$ & (0.144) & $(0.338)$ & $(0.183)$ & (0.643) \\
\hline \multirow[t]{2}{*}{ ARCH 1-1 test: $F(1,19)$} & 0.016 & 0.501 & 0.016 & 0.04 & 0.060 \\
\hline & $(0.90)$ & $(0.49)$ & $(0.901)$ & $(0.845)$ & $(0.81)$ \\
\hline \multirow[t]{2}{*}{ Normality test $C h i^{2}(2)$} & 0.881 & 0.751 & 2.502 & 0.726 & 2.551 \\
\hline & $(0.54)$ & $(0.69)$ & $(0.286)$ & $(0.696)$ & $(0.279)$ \\
\hline \multirow[t]{2}{*}{ Heteroscedasticity $F(12,8)$} & 0.362 & 0.825 & 0.248 & 0.237 & 0.139 \\
\hline & $(0.945)$ & $(0.63)$ & $(0.985)$ & $(0.987)$ & (0.999) \\
\hline$R^{2}$ & 0.56 & 0.66 & 0.22 & 0.51 & 0.68 \\
\hline$\sigma$ & 0.143 & 0.280 & 0.346 & 0.158 & 0.023 \\
\hline
\end{tabular}

Change in real credit lagged one period exerts a positive impact on growth. This effect may be channelled to real growth through positive impact of banking sector's real credit on private investment. ${ }^{1}$ Similarly, the negative impact of interest rate on real growth may be impacted through negative significant effect of real interest on private

\footnotetext{
${ }^{1}$ A voluminous empirical literature has now established a positive significant impact that real credit of the banking sector has on private investment (see, for example, Blejer and Khan, 1984; Shafik, 1990; Sundararajan and Thakur, 1980; Greene and Villanueva, 1991; Wai and Wong, 1982).
} 
investment. However, coefficients reported for both credit and interest rate appear to be insignificant in the growth equation. Coefficients on ECT in the estimated five equations reported in table (6) are consistent with weak exogeneity discussion carried out in the previous section. They appear significant in growth, private investment and interest rate equations, while reporting insignificant magnitudes in the public sector's investment and real credit equations.

\section{Conclusion and policy implications:}

Empirical discussion in this paper reveals that while investments of both public and private sectors exert positive long run effect on real output, in the short run government investment induces a crowding out impact on private investment and thereby negatively affects real growth. In view of sizable public sector in developing countries, government capital investment would have significant implications to private sector capital accumulation as well as to growth prospects. It has been simulated recently that a country should invest around 35\% of its GDP to sustain a long-run growth of $7 \%$ to realise the long-run objective of eradicating poverty and destitution. ${ }^{1}$ In the light of decreasing emphasis on state involvement in economic activities and growing movement towards more private sector participation, much of this investment should be expected to be accounted for by private sector initiatives. This has been expected to be around 22\% of GDP for Sub-Saharan Africa, implying a $10 \%$ increase over an average of nearly $12 \%$. Indeed, such a boost in private sector investment will not be enough to generate a tangible effect on long-run growth if not accompanied by increases in the 'quality' of that investment. With reference to Sudan, an increase in private investment to GDP ratio by nearly the same magnitude seems to be needed considering the $13 \%$ annual average over the last three decades. While the country achieved rates near $22 \%$ in some years in the last three decades $(1976,1981$, and 1998), the policy issue arising is how to achieve a sustainable high private investment/GDP ratio of the magnitude that is deemed conducive to enhance growth and mitigate poverty. This in part rests on tailoring a suitable, enabling macroeconomic environment to surrogate such a considerable increase in private sector capital spending.

\footnotetext{
${ }^{1}$ See Sioum, 2002, p.35.
} 
It is legitimate to assign one aspect of accommodating macroeconomic milieu to public/private balance, which poses very important implications for private sector development. The implications of nature of output or investment composition in terms of ownership for long-run growth draw on two factors. First, in view of the positive impact of private investment increase on real growth, triggering off private sector resources to the end of expanding the physical capacities of the country by increasing physical capital accumulation would be likely to contribute positively to economic growth. Second, the nature of the relationship between public sector capital and private investment in terms of whether public sector investment is adversarial or complementary to the private sector would determine the potential impact of public sector capital spending on growth and prosperity. It is in the realm of public policy thus to maintain a delicate balance as to public/private sector contribution to output and investment. The subtlety of public policy making would rest in designing and implementing the sort of state capital spending policies that target sectors where an extra unit of public capital spending contributes positively to the private sector's expected profitability. It is near total intuition that redirecting public spending towards infrastructure would have a favourable impact on private sector investment, particularly in a country plagued by supply bottlenecks. Moreover, involvement of the state's capital in sectors far from being of an infrastructural nature may jeopardise favourable effects of public sector infrastructural investment; it has been noted in this study that negative impact of public sector capital has been large enough to cancel out any positive effects. This points to selectivity in choosing government investment programmes, while it favours 'emptying' more room for private sector participation.

The privatisation programme that the government of Sudan has launched in the early 1990s seems to be a step in this direction, though it suffers several shortcomings. While it unveils an implicit recognition of the state of the potential role the private sector could undergo to foster economic growth, it fails to trigger enough capital commitments by private investors. Perhaps it is necessary to point out that many 'privatised' enterprises were actually transferred to states governments and semiindependent non-profit making organisations. Further, downsizing of the state scale in some sectors, which is potentially vital to the private sector, remains a valid issue for public policy agenda, while still consistent with the general framework of 
privatisation that the government pursues. In this regard it perhaps appropriate to mention, as examples, the state ownership of the four sugar factories, in addition to engaging in joint ventures with foreign investors in the fifth factory (the sugar industry in Sudan is comprised of only five factories producing at different levels). Moreover, needless to say that the government running quite a few textile and spinning corporations exerts a pronounced competition in a sector that is far from being characteristically infrastructural, and which features several private ventures. 


\section{References}

Aschauer, D. A. (1989), “Does Public Capital Crowd out Private Capital,” Journal of Monetary Economics, 24, September, 171-88.

Banerjee, A., J. Dolado, J. W. Galbraith, and D. F. Hendry (1993), Cointegration, Error Correction and the Econometric Analysis of Non-Stationary Data, Oxford University Press, Oxford.

Beddies, C. (1999), "Investment, Capital Accumulation and Growth: Some Evidence from the Gambia 1964-98," IMF Working Paper No. 117, IMF, Washington, D. C.

Binswanger, H. (1988), “The Impact of Infrastructure and Financial Institutions on Agricultural Output and Investment in India," mimo, World Bank.

Blejer, M. I. and M. Khan (1984), "Government Policy and Private Investment in Developing Countries," IMF Staff Papers, 31, 2, June, 379-403.

Brownbridge, M. (1994), Private Investment and Structural Adjustment in Developing Countries, unpublished Ph.D. thesis, IDPM, University of Manchester, England.

Buiter, W. H. (1977), "Crowding-Out and the Effectiveness of Fiscal Policy," Journal of Public Economics, 7, 309-328.

Charemza, W. W. and D. F. Deadman (1997), New Directions in Econometric Practice: General to Specific Modeling, Cointegration and Vector Autoregression, $2^{\text {nd }}$ edition, Edward Elgar Publishing, Cheltenham.

Chhibber, A. and S. van Wijnbergen (1988), "Public Policy and Private Investment in Turkey," Working Paper No. 120, World Bank.

David, P. and J. Scadding (1974), "Private Savings: Ultrarationality, Aggregation, and 'Dension's Law',' Journal of Political Economy, 82, 225-249.

Davidson, J., D. F. Hendry, F. Srba, and S. Yeo (1978), "Econometric Modelling of the Aggregate Time Series Relationship Between Consumers' Expenditure and Income In the United Kingdom,” The Economic Journal, 88, 661-92.

Davidson, J. (1998), "Structural Relations, Cointegration and Identification: Some Simple Results and their Application," Journal of Econometrics, 87, 87-113.

Dicky, D. A. and W. A. Fuller (1979), "Distributions of Estimators for Autoregressive Time Series with a Unit Root," Journal of the American Statistical Association, 74, 427-431. 
Dicky, D. A. and W. A. Fuller (1981), "Likelihood Ratio Statistics for Autoregressive Time Series with a Unit Root," Econometrica, 49, 1057-1072.

Doornik, A. J. and D. F. Hendry (2001), Modelling Dynamic Systems Using PcGive 10, Volume II, Timberlake Consultants Ltd., London.

Easterly, W. and R. Levine (2001), "It's not Factor Accumulation: Stylized Facts and Growth Models," The World Bank Economic Review, 15, 2, 177-219.

Engle R. F., D. F. Hendry, and J-F Richard (1983), "Exogeneity," Econometrics, 51, 277-304.

Engle R. F., D. F. Hendry, and J-F Richard (1994), "Exogeneity," in Testing Exogeneity, 39-70, N. R. Ericsson and J. S. Irons (eds.), Oxford University Press, Oxford.

Ericsson R., D.F. Hendry, and E. Mizon (1998), "Exogeneity, Cointegration, and Economic Policy Analysis," Journal of Business and Economic Statistics, 16, 4, 370-87.

Ermisch, J. F. and W. G. Huff (1999), "Hyper growth in an East Asian NIC: Public Policy and Capital Accumulation in Singapore," World Development, 27, 1, 21-38.

Galbis, V. (1979), "Money, Investment and Growth in Latin America, 1961-1973," Economic Development and Cultural Change, 27, April, 423-43.

Ghali, K. H. (1998), "Public Investment and Private Capital Formation in a Vector Error Correction Model of Growth," Applied Economics, 30, 837-844.

Granger, C.W. J. (1969), "Investigating Causal Relations by Econometric Models and Cross-Spectral Methods," Econometrica, 37, 24-36.

Greene, J. and D. Villanueva (1991), "Private Investment in Developing Countries: An Empirical Analysis," IMF Staff Papers, 38,1, 33-58.

Harberger, A. C. (1972), "On Measuring the Social Opportunity Cost of Public Funds," in Project Evaluation: Collected Papers, A. Harberger (ed.), Chicago.

Heller, P. S. (1975), “A Model of Public Fiscal Behaviour in Developing Countries: Aid, Investment, and Taxation," The American Economic Review, 65, June, 429-45.

Hendry, D. F. and G. J. Anderson (1977), “Testing Dynamic Specification in Small Simultaneous Models: An Application to a Model of Building Society Behavior in the United Kingdom," in Frontiers of Quantitative Economics, 361-383, M. D. Intrilligator (ed.), North-Holland, Amsterdam. 
Johansen, S. (1988), "Statistical Analysis of Cointegration Vectors," Journal of Economic Dynamics and Control, 110, 495-525.

Jones, C. (1995), “Time Series Tests of Endogenous Growth Models,” The Quarterly Journal of Economics, 110, 495-525.

Khan, M. (1996), “Government Investment and Economic Growth in the Developing World," Pakistan Development Review, 35, 4, 419-39.

Khan, M. and C. M. Reinhart (1990), "Private Investment and Economic Growth in Developing Countries," World Development, 18, 1, 19-27.

Khan, M. and M. S. Kumar (1997), "Public and Private Investment and the growth process in developing Countries," Oxford Bulletin of Economics and Statistics, $59,1,69-88$.

King, R. G. and R. Levine (1994), “Capital Fundamentalism, Economic Development, and Economic Growth," Carnegie-Rochester Conference Series on Public Policy, 40, 259-292.

Lee, K. S. (1991), "Private Alternatives to Public Sector Investment Deficiencies: The Case of Nigerian Manufacturing," in Analytics of Economic Reforms in Sub-

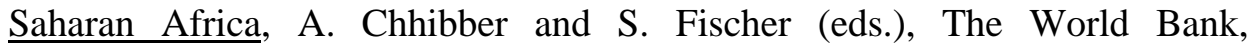
Washington D. C.

Naqvi, N. H. (2002), "Crowding-in or Crowding-out? Modelling the Relationship between Public and Private Capital Formation using Cointegration Analysis: The Case of Pakistan 1964-2000," Paper Presented at the Development Economics Study Group Annual Conference, 18-20 April 2002, School of Economics, University of Nottingham, England.

Ogura, S. and G. Yohe (1977), “ The Complementarity of Public and Private Capital and the Optimal Rate of Return to Government Investment," The Quarterly Journal of Economics, XCI, 651-62.

Pereira, A. M. (2000), “Is All Public Capital Created Equal?," Review of Economics and Statistics, 82, 3, 513-518.

Pereira, A. M. (2001), “On the Effects of Public Investment on Private Investment: What Crowds in What?," Public Finance Review, 29, 1, 3-25.

Podrecca, E. and G. Carmeci (2001), "Fixed Investment and Economic Growth: New Results on Causality," Applied Economics, 33, 177-182. 
Ram, R. (1996), "Productivity of Public and Private Investment in Developing Countries: A broad International Perspective," World Development, 24, 8, 1373-1378.

Rama, M. (1990), "Empirical Investment Equations in Developing Countries," Working Paper No. 563, December, Country Economics Department, World Bank.

Sandmo, A. and J. Dreze (1971), "Discount Rates for Public Investment in Closed and Open Economies," Economica, XXXVIII, 395-412.

Sargent, T. J. (1976), "A Classical Macroeconomic Model for the United States," Journal of Political Economy, 84, 207-38.

Shafik, N. (1990), "Modeling Investment Behaviour in Developing Countries: An Application to Egypt," PRE Working Paper No. 452, World Bank.

Sim, C. A. (1980), “Macroeconomics and Reality,” Econometrica, 48, 1-48.

Sioum, A. S. (2002), "Private Investment and Public Policy in Sub-Saharan Africa: An Empirical Analysis," Institute of Social Studies Working Paper No. 356, January, The Hague, The Netherlands.

Sundararajan, V. and S. Thakur (1980), "Public Investment, Crowding Out, and Growth: A Dynamic Model Applied to India and Korea," IMF Staff Papers, $27,814-55$.

von Furstenberg, M. and B. G. Malkiel (1977), "The Government and Capital Formation: A Survey of Recent Issues," Journal of Economic Literature, 15, September, 835-78.

Wai U T. and C. Wong (1982), "Determinants of Private Investment in Developing Countries," Journal of Development Studies, 19, October, 19-36. 